\title{
WATER VAPOUR MIXING RATIO MEASUREMENTS IN POTENZA IN THE FRAME OF THE INTERNATIONAL NETWORK FOR THE DETECTION OF ATMOSPHERIC COMPOSITION CHANGE - NDACC
}

\author{
Benedetto De Rosa*, Paolo Di Girolamo*, Donato Summa, Dario Stelitano, Ignazio Mancini \\ Scuola di Ingegneria, Università degli Studi della Basilicata, Viale dell'Ateneo Lucano n. 10, 85100 \\ Potenza-Italy,*Emails: bundit@hotmail.it; digirolamo@unibas.it
}

\begin{abstract}
In November 2012 the University of BASILicata Raman Lidar system (BASIL) was approved to enter the International Network for the Detection of Atmospheric Composition Change (NDACC). This network includes more than 70 high-quality, remote-sensing research stations for observing and understanding the physical and chemical state of the upper troposphere and stratosphere and for assessing the impact of stratosphere changes on the underlying troposphere and on global climate. As part of this network, more than thirty groundbased Lidars deployed worldwide are routinely operated to monitor atmospheric ozone, temperature, aerosols, water vapour, and polar stratospheric clouds.

In the frame of NDACC, BASIL performs measurements on a routine basis each Thursday, typically from local noon to midnight, covering a large portion of the daily cycle. Measurements from BASIL are included in the NDACC database both in terms of water vapour mixing ratio and temperature. This paper illustrates some measurement examples from BASIL, with a specific focus on water vapour measurements, with the goal to try and characterize the system performances.
\end{abstract}

\section{INTRODUCTION}

Water vapour is a key atmospheric trace gas controlling weather and climate. The effects of water vapour are large in the upper troposphere and lower stratosphere, but there are few measurements of water vapour concentrations and its long-term variation in this altitude region. Measurements in this altitude region have been traditionally guaranteed by the use of operational radiosondes or balloon-borne frost-point hygrometers, the latter remaining the best source of high quality water vapour measurements in the in the UTLS region[1], but being yet too expensive to be used on operational basis.

For the above motivations, in the early 2000 s, the international Network for the Detection of Stratospheric Change (NCSC), now Network for the Detection of Atmospheric Composition Change (NDACC), decided to include water vapour Raman lidars among its instruments.

In fact, while NDACC remains committed to long-term monitoring of changes in the stratosphere, with an specific emphasis on the evolution of the ozone layer, its priorities have broadened to include issues such as the detection of trends in the overall atmospheric composition and understanding their impacts on the stratosphere and troposphere, and establishing links between climate change and atmospheric composition.

The Raman Lidar system BASIL joined NDACC in November 2012, with the primary goal of providing accurate routine measurements of the vertical profile of water vapour mixing ratio and temperature, these two parameters being of primary importance for the purposes of NDACC, with valuable contribution to the NDACC primarily expected in terms of water vapour measurements.

\section{BASIL}

Lidar measurements discussed in this paper were performed by the Raman Lidar system BASIL in Potenza, Italy $\left(40^{\circ} 38^{\prime} 45^{\prime \prime} \mathrm{N}, 15^{\circ} 48^{\prime} 29^{\prime \prime} \mathrm{E}, 730 \mathrm{~m}\right.$ above mean sea level). The system is hosted in a sea-tainer located on the roof of the Scuola di Ingegneria at the Università degli Studi della Basilicata. The major feature of BASIL is represented by its capability to perform highresolution and accurate measurements of atmospheric water vapour and temperature, both in daytime and nighttime, based on the application of the vibrational and rotational Raman lidar techniques in the UV $[2,3,4,5,6]$. Besides water 
vapour and temperature, BASIL, in its NDACC configuration, also provides measurements of particle backscatter at 355 and $532 \mathrm{~nm}$, particle extinction at $355 \mathrm{~nm}$ and particle depolarization at $355 \mathrm{~nm}$. and water vapor mixing ratio. All lidarbased measurements of relative humidity can also be obtained from the simultaneous water vapor mixing ratio and temperature measurements.

As stated in the affiliation letter a valuable contribution to the NDACC from BASIL is primarily expected in terms of water vapour mixing ratio measurements. For this reason, a major emphasis has been put on this parameter, especially in terms of calibration and validation efforts.

In the frame of NDACC, BASIL operates on a routine basis each Thursday, typically from local noon to midnight, covering a large portion of the daily cycle. Water vapour mixing ratio measurements routinely performed by BASIL in the frame of the NDACC program, besides being included in the long-term measurement activities NDACC database, are also used for the purpose of validating the water vapor measurements from other sensors, especially satellite-borne sensors, of studying upper tropospheric humidity variability at timescales varying from minutes to days.

BASIL makes use of a Neodymium-doped Yttrium Aluminium Garnet (Nd:YAG) laser source, equipped with second and third harmonic generation crystals and capable of emitting pulses at 355 and $532 \mathrm{~nm}$, with single pulse energies of 500 and $300 \mathrm{~mJ}$, respectively, a pulse repetition rate of $20 \mathrm{~Hz}$ and a pulse duration of 5-6 ns. Laser beams at 355 and $532 \mathrm{~nm}$ are simultaneously transmitted in the atmosphere along the zenith.

The receiver is built around a telescope in Newtonian configuration $(40-\mathrm{cm}$ diameter primary mirror). Collected radiation is split into eight separate portions by means of dichroic or partially reflecting mirrors. Specifically, two portions are fed into the detection channels used for temperature measurements; two other portions are sent to the water vapour and nitrogen Raman channels; another two portions are fed into the 355 and $532 \mathrm{~nm}$ elastic channels; and a fraction of the signal entering the $355-\mathrm{nm}$ channel is split into two additional portions to allow the detection of the parallel and cross-polarized elastic signals used for the determination of particle depolarization.
Signal selection is performed by means of narrowband interference filters, while signal detection is accomplished by means of photomultipliers located in cascade with each interference filter; detected signals are finally sampled by means of photon-counting units. Data are acquired with a vertical and temporal resolution of $30 \mathrm{~m}$ and $1 \mathrm{~min}$, respectively. A block diagram of the system is given in Fig.1.

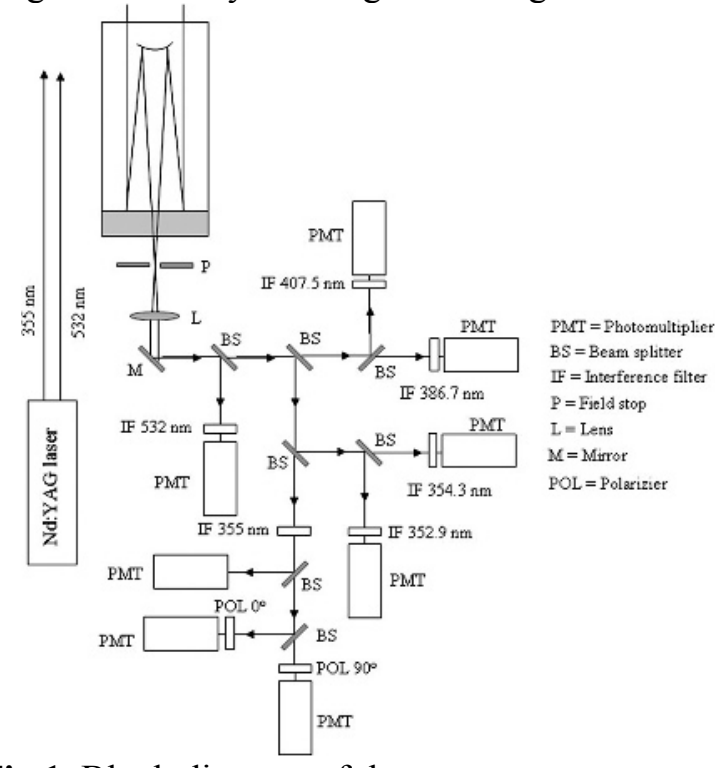

Fig.1. Block diagram of the system setup.

\section{METHODOLOGY}

The Raman lidar technique for the determination of the water vapor mixing ratio profile has been extensively discussed in literature (for a review see Whiteman 2003a and 2003b). The approach is based on the collection of the vibrational Raman backscattered signals from water vapour and nitrogen molecules, i.e.:

$$
\begin{aligned}
& P_{\mathrm{H}_{2} \mathrm{O}}(R)=P_{0} \frac{c \Delta t}{2} \frac{A_{t e l}}{R^{2}} O(R) n_{\mathrm{H}_{2} \mathrm{O}}(R) \sigma_{\mathrm{H}_{2} \mathrm{O}} T_{\lambda_{\mathrm{O}}}(R) T_{\lambda_{\mathrm{H}_{2} \mathrm{O}}}(R) \\
& P_{\mathrm{N}_{2}}(R)=P_{0} \frac{c \Delta t}{2} \frac{A_{t e l}}{R^{2}} O(R) n_{N_{2}}(R) \sigma_{N_{2}} T_{\lambda_{0}}(R) T_{\lambda_{N_{2}}}(R)
\end{aligned}
$$

The water vapour mixing ratio $x_{H_{2} \mathrm{O}}(R)$ can be obtained from the power ratio of water vapour to molecular nitrogen vibrational Raman signals through the application of the expression:

$$
x_{\mathrm{H}_{2} \mathrm{O}}(R)=k \frac{P_{\mathrm{H}_{2} \mathrm{O}}(R)}{P_{\mathrm{N}_{2}}(R)} \Delta T_{\lambda_{\mathrm{H}_{2} \mathrm{O}}, \lambda_{N_{2}}}
$$


with $k$ being the lidar system calibration coefficient and $\Delta T_{\lambda_{\mathrm{H}_{2} \mathrm{O}}, \lambda_{\mathrm{N}_{2}}}=T_{\lambda_{\mathrm{N}_{2}}}(R) / T_{\lambda_{\mathrm{H}_{2} \mathrm{O}}}(R)$ being the differential transmission term, which accounts for the different atmospheric transmission at the two Raman wavelengths $\lambda_{\mathrm{H}_{2} \mathrm{O}}$ and $\lambda_{\mathrm{N}_{2}}$. When stimulated at $354.7 \mathrm{~nm}$ the water vapour and molecular nitrogen vibrational Raman signals are located at $\lambda_{\mathrm{H}_{2} \mathrm{O}}=407.5 \mathrm{~nm}$ and $\lambda_{\mathrm{N}_{2}}=386.7 \mathrm{~nm}$, respectively. $\Delta T_{\lambda_{H_{2} O}, \lambda_{N_{2}}}$ is primarily caused by Rayleigh scattering and can easily be corrected for by the use of radiosonde or standard-atmospheric profiles of number density. An additional component of $\Delta T_{\lambda_{H_{2} \mathrm{O}}, \lambda_{N_{2}}}$ is associated with the wavelength dependence of particle extinction, which is usually very small ( $1-2 \%)$ and is easily determinable from lidar measurements of particle extinction at $354.7 \mathrm{~nm}$ (Whiteman, 2003b).For the purposes of NDACC the calibration coefficient $\mathrm{k}$ was determined based on the comparison between simultaneous and co-located water vapour mixing ratio profiles from the Raman lidar and radiosondes for an extended measurement sample. The comparison is performed over an altitude region with an extent of 1-3 km in order to have a statistical significant number of data points per profile to be compared. The selection of this altitude region accounts for the existing distance between the lidar site and the radiosonde launching facility.

The statistical error is calculated by means the analytical expression :

$$
\Delta \chi_{H 2 O}(z)=\chi_{H 2 O}(z) \sqrt{\frac{P_{H 2 O}(z)+b_{H 2 O}}{\left[P_{H 2 O}(z)\right]^{2}}+\frac{P_{N 2}(z)+b_{N 2}}{\left[P_{N 2}(z)\right]^{2}}}
$$

\section{RESULTS}

As an example of the measurements carried out in the frame of NDACC, figure 2 illustrates the time evolution of the water vapor mixing ratio over a 7 $\mathrm{h}$ period of from 16:36 UTC to 23:22 UTC on 09 October 2014. Figure 2 is plotted as a succession of $1 \mathrm{~min}$ averaged consecutive profiles. To reduce signal statistical fluctuations, vertical smoothing is applied to the data to achieve an overall vertical resolution of $150 \mathrm{~m}$. The figure clearly highlights the day-to-night transition, with the final part of the daytime portion clearly distinguishable on the left side of the figure with noisy data above 4-5 $\mathrm{km}$.

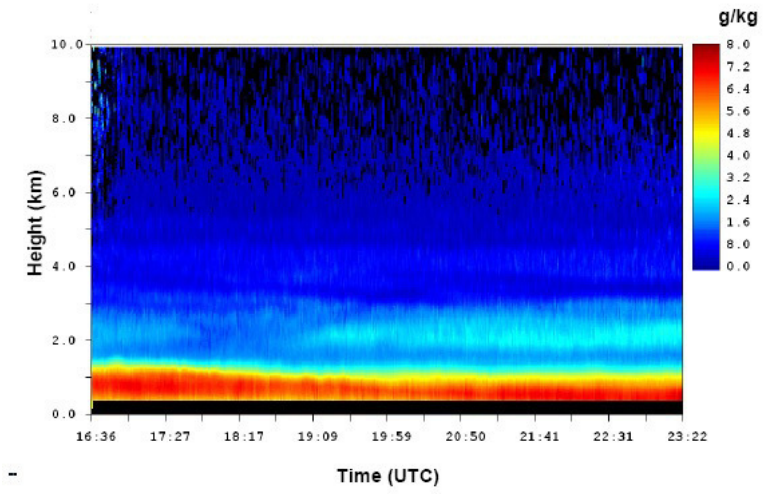

Fig. 2. Time evolution of the water vapor mixing ratio over a $7 \mathrm{~h}$ period of from 16:36 UTC to 23:22 UTC on 09 October 2014.

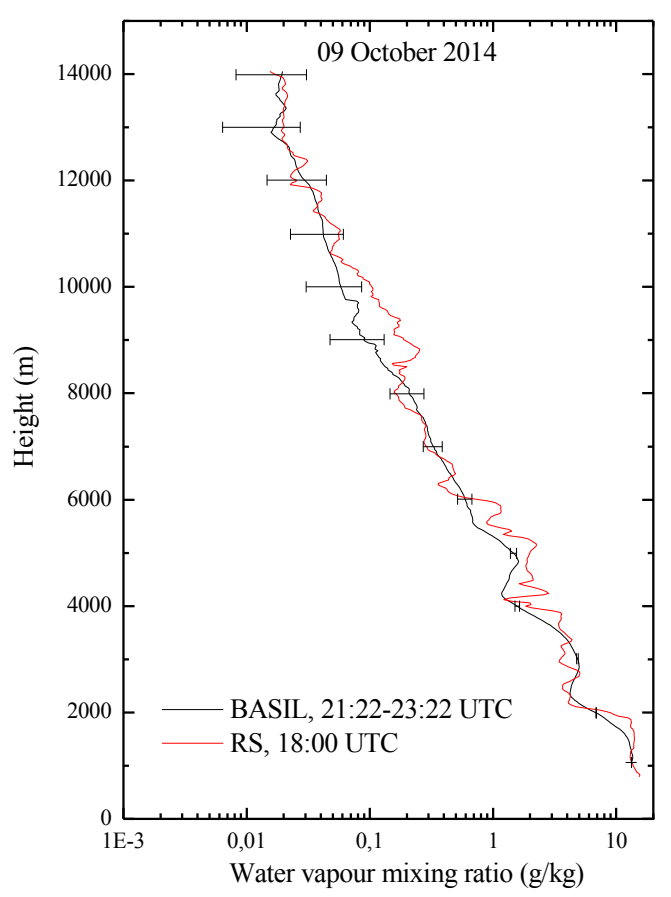

Fig. 3. Vertical profile of the water vapour mixing ratio with the error bars as obtained considering a $2 \mathrm{~h}$ time integration between 21:22 and 23:22 UTC on 09 October 2014, together with the simultaneous profile as measured by a radiosonde launched from the nearby site of Tito Scalo at 18:00 UTC on 09 October 2014. 
Figure 3 illustrates the vertical profile of the water vapour mixing ratio as obtained for the same day considering a $2 \mathrm{~h}$ time integration between 21:22 and 23:22 UTC. The vertical resolution is $300 \mathrm{~m}$ up to $6 \mathrm{~km}, 600 \mathrm{~m}$ up to $9 \mathrm{~km}$ and $1200 \mathrm{~m}$ above. For comparison the almost simultaneous water vapour mixing ratio profile as measured by a radiosonde launched from the nearby site of Tito Scalo (7 km away) at 18:00 UTC on 09 October 2014. The agreement between BASIL and the radiosonde is quite good, especially when considering the distance between the two sites. The lidar profile from BASIL is found to reach approx. $14 \mathrm{~km}$, with a capability to go down to $0.02 \mathrm{~g} / \mathrm{kg}$. The capability to reach $14-15 \mathrm{~km}$ and a detection level of $0.01-0.02 \mathrm{~g} / \mathrm{kg}$ has been observed in most of the $2 \mathrm{~h}$ averaged clear sky measurements from BASIL in the frame of NDACC. In the case of measurements integrated over all night, the lidar profile from BASIL is found to reach approx. $18-20 \mathrm{~km}$. More results from this measurement effort, also focused on a statistical analysis on the collected data, will be illustrated and discussed at the Conference.

\section{ACKNOWLEDGEMENT}

We wish to warmly thank Istituto di Metodologie per l'Analisi Ambientale, Consiglio Nazionale delle Ricerche, in Tito Scalo, for the provision of the radiosnde data.

\section{REFERENCES}

[1] Vomel, H., H. Selkirk, L. Miloshevich, J. Valverde-Canossa, J. Valdes, E. Kyro, R. Kivi, W. Stolz, G. Peng, and J. A. Diaz,2007: Radiation dry bias of the Vaisala RS92 humidity sensor. J. Atmos. Oceanic Technol., 24, 953-963.
[2] Whiteman, D. N., 2003: Examination of the traditional Raman lidar technique. I. Evaluating the temperature-dependent lidar equations, Appl. Opt., 42, 2571-2592.

[3] Behrendt, A. and Reichardt, J.: Atmospheric temperature profiling in the presence of clouds with a pure rotational Raman lidar by use of an interference-filter-based polychromator, Appl. Optics, 39, 1372-1378, 2000.

[4] Di Girolamo, P., R. Marchese, D. N. Whiteman, B. B. Demoz, 2004: Rotational Raman Lidar measurements of atmospheric temperature in the UV. Geophys. Res. Lett., 31, doi: 10.1029/2003GL018342.

[5] Di Girolamo, P., A. Behrendt, and V. Wulfmeyer, 2006. Spaceborne profiling of atmospheric temperature and particle extinction with pure rotational Raman lidar and of relative humidity in combination with differential absorption lidar: performance simulations, Appl. Opt., 45, 2474-2494, doi:10.1364/AO.45.002474.

[6] Bhawar, R., P. Di Girolamo, D. Summa, C. Flamant, D. Althausen, A. Behrendt, C. Kiemle, P. Bosser, M. Cacciani, C. Champollion, T. Di Iorio, R. Engelmann, C. Herold, Müller, D., S. Pal, M. Wirth, V. Wulfmeyer, 2011: The Water Vapour Intercomparison Effort in the Framework of the Convective and Orographically-Induced Precipitation Study: Airborne-to-Ground-based and airborne-to-airborne Lidar Systems, Quarterly Journal of the Royal Meteorological Society, 137, 325-348. 